\title{
Effects of different heating patterns on the decomposition behavior of white pine wood during slow pyrolysis
}

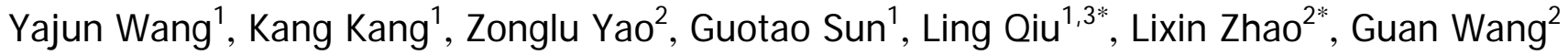 \\ (1. College of Mechanical and Electronic Engineering, Northwest A\&F University, Yangling 712100, China; 2. Key Laboratory of \\ Energy Resource Utilization from Agricultural Residues, Chinese Academy of Agricultural Engineering, Beijing 100125, China; \\ 3. Northwest Research Center of Rural Renewable Energy Exploitation and Utilization, Ministry of Agriculture and Rural Affairs, \\ Yangling 712100, China)
}

\begin{abstract}
This study investigated the effect of different heating rates on the pyrolysis behavior of the white pine wood residues. The raw materials were tested via two heating patterns with variable heating rates and compared with three other heating patterns with constant heating rates. The yields and characteristics of products such as char, pyrolysis oil and non-condensable gases under different heating rates were also determined. The gas, liquid, and solid phase yields of the products via heating with decreasing heating rates were similar to the yields obtained from constant heating rate at $2.3^{\circ} \mathrm{C} / \mathrm{min}$. The pyrolysis process by decreasing heating rates resulted in $30.04 \%$ char, $44.53 \%$ bio-oil, and $25.43 \%$ non-condensable gases, which displayed higher char yield and pyrolysis gas than the other heating patterns. The results of thermo-gravimetric analysis showed that variable heating rate significantly changed the weight loss profiles during pyrolysis. It was observed during gas chromatography test that $\mathrm{CO}$ and $\mathrm{CO}_{2}$ were released earlier than $\mathrm{CH}_{4}$ and $\mathrm{H}_{2}$. The analysis of the chemical components confirmed that the bio-oil produced by heating process with decreasing rates contains less macromolecular organic matter content than the other patterns.
\end{abstract}

Keywords: pyrolysis, variable heating rates, constant heating rate, product yields

DOI: $10.25165 /$ j.ijabe.20181105.3156

Citation: Wang Y J, Kang K, Yao Z L, Sun G T, Qiu L, Zhao L X, et al. Effects of different heating patterns on the decomposition behavior of white pine wood during slow pyrolysis. Int J Agric \& Biol Eng, 2018; 11(5): 218-223.

\section{Introduction}

With the rapid increase in energy demand and global warming, bio-fuels as renewable energy sources were considered as one of the key options to substitute conventional fuels. In China, huge amount of agricultural residues or biomass waste are produced every year, which are considered as the potential sources for renewable energy.

Combustion, anaerobic digestion and thermochemical conversions have been widely studied as biomass conversion routes. It was confirmed by many literatures that thermochemical routes can generate useful products including charcoal, gas and bio-oil. Pyrolysis properties (reaction kinetics, products yields and composition) are influenced by many parameters such as biomass types, temperature, heating rate, particle size, reaction atmosphere, and vapor residence time $\mathrm{e}^{[1-3]}$. Fast pyrolysis technology has been intensively investigated for bio-oil production in recent years ${ }^{[4]}$.

Receive date: 2016-12-31 Accepted date: 2018-08-03

Biographies: Yajun Wang, $\mathrm{PhD}$ candidate, research interest: agricultural waste disposal, Email: wangyajunkaka@outlook.com; Kang Kang, PhD, research interest: high quality utilization of waste, Email: kknwafu@hotmail.com; Zonglu Yao, PhD, research interest: high quality utilization of waste, Email: yaozonglu@163.com; Guotao Sun, PhD, research interest: bioenergy engineering, Email: 445490135@qq.com; Guan Wang, PhD candidate, research interest: bioenergy engineering, Email: wangguanxianger@126.com.

*Corresponding author: Ling Qiu, PhD, Professor, research interest: bioenergy engineering, College of Mechanical and Electronic Engineering, Northwest A\&F University, Yangling 712100, China. Tel: +86-13992873650, Email: QL2871@126.com; Lixin Zhao, PhD, Professor, research interest: bioenergy engineering, Chinese Academy of Agricultural Engineering, Beijing 100125, China. Email: zhaolixin5092@163.com.
Lower process temperatures $(673 \mathrm{~K})$ and long vapor residence times were favors the production of charcoal. High temperatures (1023K-1173K) and longer residence times increase biomass gasification rate, however, moderate temperatures $(773 \mathrm{~K})$ and short vapor residence times are the optimal conditions for liquid (bio-oil) production ${ }^{[5,6]}$.

Charcoal is the solid carbonaceous product with enriched fixed carbon, which can be used directly as a fuel, fertilizer or precursor for activated carbon production ${ }^{[7]}$. The quality of char is determined by its physicochemical characteristics such as volatile matter, fixed carbon, ash content, carbon content and higher heating value ${ }^{[8]}$. In the study of Zhou ${ }^{[9]}$, the property of charcoal was determined in relation to pyrolysis temperatures and particle size of the raw material. Onay ${ }^{[10]}$ found that the changes of heating rates resulted in different extent of the pyrolysis and thus resulted in different char structure. Haykiri-Acma et al. ${ }^{[11]}$ found that the maximum mass losses were directly proportional to the heating rates.

The pyrolysis oil contains different chemicals with various functional groups including acids, sugars, alcohols, ketones, aldehydes, phenols and their derivatives, furans and other mixed oxygenates $^{[12-14]}$, which makes isolation and purification of the bio-oil difficult. Bio-oil derived from the pyrolysis process has a significantly lower heating value (14-18 $\mathrm{MJ} / \mathrm{kg})$ than gasoline. Due to the low heating value, pyrolysis gas is better suited for heating or feedstock drying than for power generation ${ }^{[15]}$. The mixture of non-condensable gases produced during pyrolysis consists of a number of combustible gases such as $\mathrm{CO}, \mathrm{CH}_{4}, \mathrm{H}_{2}$, C2-hydrocarbons, as well as a high concentration of incombustible $\mathrm{CO}_{2}{ }^{[16]}$. This study mainly explored the effects of different 
heating patterns with variable heating rates on the decomposition behavior of white pine wood during slow pyrolysis. The main objective of this study is to optimize the product yields and quality of charcoal, pyrolysis gas and bio-oil by investigating different heating patterns such as variable heating rate and constant heating rate.

\section{Materials and methods}

\subsection{Raw materials analysis}

White pine wood residues were collected from a fuel factory located in Beijing, China. The samples were screened to the same particles sizes of 5-6 $\mathrm{mm}$ and dried for $3 \mathrm{~h}$ at $(105 \pm 5)^{\circ} \mathrm{C}$. Proximate and elemental analyses were performed on the samples to determine their basic physiochemical properties. In addition, hemicellulose, cellulose and lignin content were tested following the methods of AOAC/AACC and AOCS. Proximate analysis was conducted following the ASTM D3173 and D3175 standards. The elemental composition was analyzed by an automatic elemental analyzer (EA3000). The $\mathrm{C}, \mathrm{H}, \mathrm{N}$, and $\mathrm{O}$ content in the biomass and charcoal were analyzed by using high temperature combustion method, and the results are shown in Table 1.

Table 1 Chemical analysis results of the samples

\begin{tabular}{lc}
\hline Components/wt\% & White pines \\
\hline Volatiles & 81.01 \\
Fixed carbon & 11.98 \\
Ash & 0.95 \\
Moisture & 6.06 \\
Hemicellulose & 24.11 \\
Cellulose & 42.26 \\
Lignin & 26.69 \\
C & 49.44 \\
H & 6.33 \\
O & 43.85 \\
N & 0.38 \\
\hline
\end{tabular}

\subsection{Slow pyrolysis experiments}

Pyrolysis was carried out using a lab-scale fixed bed reactor with length of $800 \mathrm{~mm}$ and internal diameter of $100 \mathrm{~mm}$, which was heated externally by an electrical furnace and continually purged with nitrogen gas. The outlet of the pyrolysis reactor was connected to a condenser and a gas flow meter for detecting the non-condensing gas. Schematic figure of the pyrolysis unit is shown in Figure 1. Biomass feedstock (200 g) was used for each test. Two heating patterns, decreasing heating rate (DHR) and accelerating heating rate (AHR), with three other heating patterns with constant heating rates were tested as shown in Figure 2 with initial temperature at $40^{\circ} \mathrm{C}$. The changing points of the heating patterns were selected based on the pyrolysis characteristics of hemicellulose, cellulose and lignin. Studies suggested that hemicellulose and cellulose pyrolysis reactions ranged from $200^{\circ} \mathrm{C}$ to $360^{\circ} \mathrm{C}$. The reaction temperature range of lignin can be extended to more than $500^{\circ} \mathrm{C}^{[17]}$. In addition, to ensure a higher char yield and lower liquid yield, the heating rate is normally lower than $30^{\circ} \mathrm{C} / \mathrm{min}^{[18-21]}$.

For Pattern 1, named as DHR, $200^{\circ} \mathrm{C}$ and $360^{\circ} \mathrm{C}$ were selected as the changing points to separate the three reaction phases with different heating rates of $20^{\circ} \mathrm{C} / \mathrm{min}, 10^{\circ} \mathrm{C} / \mathrm{min}$ and $2{ }^{\circ} \mathrm{C} / \mathrm{min}$, respectively. While for Pattern 2, named as AHR, the three reaction phases were set with different heating rates of $2^{\circ} \mathrm{C} / \mathrm{min}$, $10^{\circ} \mathrm{C} / \mathrm{min}$ and $20^{\circ} \mathrm{C} / \mathrm{min}$, respectively. Heating rates for Patterns
3 , 4 and 5 were fixed at $4.6^{\circ} \mathrm{C} / \mathrm{min}, 2.3^{\circ} \mathrm{C} / \mathrm{min}$ and $9.2^{\circ} \mathrm{C} / \mathrm{min}$, respectively. Heating rate of $4.6^{\circ} \mathrm{C} / \mathrm{min}$ in Pattern 3 guaranteed its pyrolysis time was in common with Patterns 1 and 2 . The final pyrolysis temperatures of all five experiments were all set at $520^{\circ} \mathrm{C}$. During the pyrolysis of the raw materials, the $\mathrm{N}_{2}$ was purged at a flow rate of $100 \mathrm{~mL} / \mathrm{min}$ to remove the gas phase products. Pyrolysis gases were sampled with collection bags after being condensed, $50 \mathrm{~mL}$ gas was collected every $10 \mathrm{~min}$.

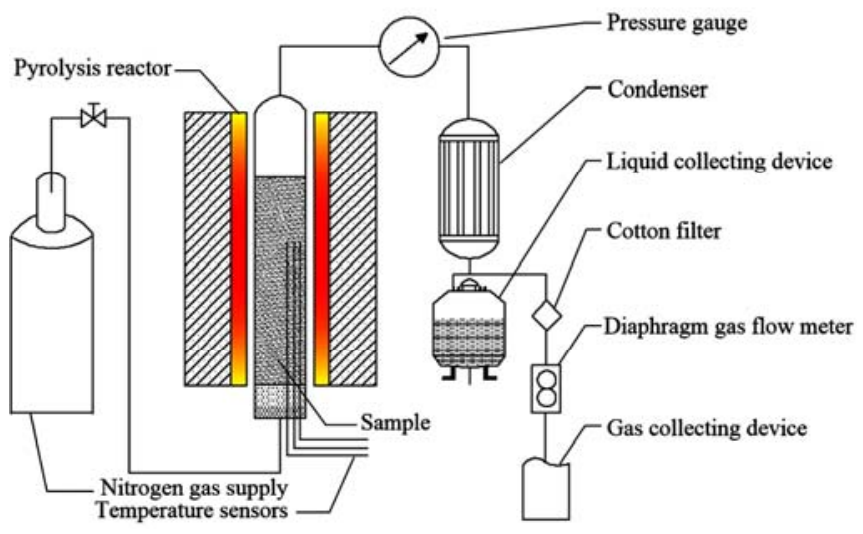

Figure 1 Schematic view of the pyrolysis unit

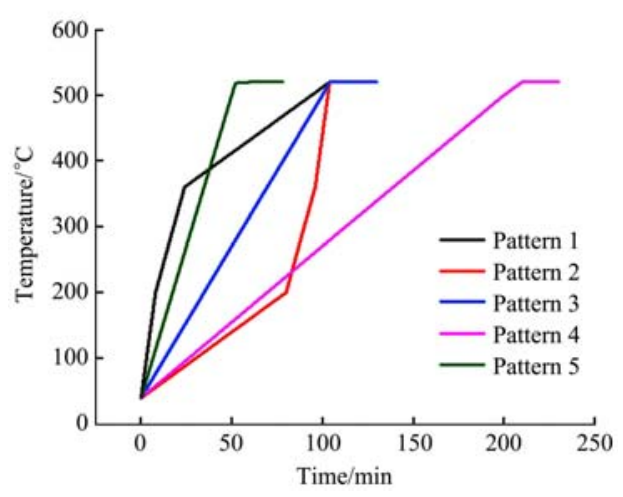

Figure 2 Five heating patterns

\subsection{Char analysis}

Thermo-gravimetric analysis (TGA) was carried out using a TGA analyzer (TG-60) to determine the characteristic of pyrolysis. In addition to particle size (1-2 $\mathrm{mm})$, the processing conditions (heating rate, final pyrolysis temperature, etc.) were identical to that of the fixed bed. The TGA analysis can eliminate the temperature lag problems caused by the heat conduction, which then allow for more accurate characterization pyrolysis behavior of the sample $e^{[22,23]}$. In addition, the method of proximate and elemental analyses used for the char samples were the same as that been used for the raw material. The higher heating value (HHV) of charcoal and raw materials were analyzed using a bomb calorimeter (ZDHW-5000).

\subsection{Gas and bio-oil analysis}

Composition of the pyrolysis gas was detected using a gas chromatography (GC). The column temperature was set at $100^{\circ} \mathrm{C}$, and preheated for $5 \mathrm{~h}$ before test. The chromatographic column TDX-01 ( $3 \mathrm{~m} \times 3 \mathrm{~mm})$ was used in this test. The carrier gas was helium with the pressure of $0.2 \mathrm{MPa}$.

The chemical components of heavy oil in bio-oil were determined using GC-MS following the area normalization method. The GC-MS (DSQ) was equipped with an AB-5MS capillary column (30 $\mathrm{m} \times 0.25 \mathrm{~mm} \times 0.25 \mu \mathrm{m}$ ), and was used to identify the chemical compounds contained in the bio-oil. Initial column temperature was maintained at $80^{\circ} \mathrm{C}$ for $3 \mathrm{~min}$ and then raised to $300^{\circ} \mathrm{C}$ at the heating rate of $3^{\circ} \mathrm{C} / \mathrm{min}$. 


\section{Results and discussion}

\subsection{Effect of heating rate on pyrolysis process and product compositions}

To explore the effect of different heating rates on pyrolysis process and product yields, five heating patterns were tested as shown in Figure 2. Patterns 1, 2 and 3 had the same heating-up time and holding time. In Patterns 3, 4 and 5, product yields were generated by pyrolysis under different constant heating rates.

In terms of product yield distribution, the gas, liquid and solid phase yields of Pattern 1 are similar to that of Pattern 4. Pattern 1 achieved the highest mass proportion of gas yield of $25.43 \%$ with the lowest bio-oil yield at $44.53 \%$ (Figure 3). It was found that more charcoals were produced by Patterns 1 and 4 than Patterns 2, 3 and 5. Although Pattern 4 had the highest char yield of $31.09 \%$, it required heating-up time of $208 \mathrm{~min}$, which is two times of that in Pattern 1. To obtain high char yield with reduced heating-up time, Pattern 1 had a better performance than Pattern 4. Patterns 1 and 4 had the similar heating rates $\left(2^{\circ} \mathrm{C} / \mathrm{min}\right.$ and $\left.2.3^{\circ} \mathrm{C} / \mathrm{min}\right)$ in high temperature region which was higher than $360^{\circ} \mathrm{C}$. Their heating rates were lower than the other three patterns and obtained the similar gas, liquid and solid phase yields. It could be also concluded that heating rates in the high-temperature region is a key factor affecting product yields. It also can be explained by the observations reported by previous literatures ${ }^{[4,24,25]}$, that intensive fracture and reorganization of functional groups occurred in the high-temperature region, which significantly changed the product yields.

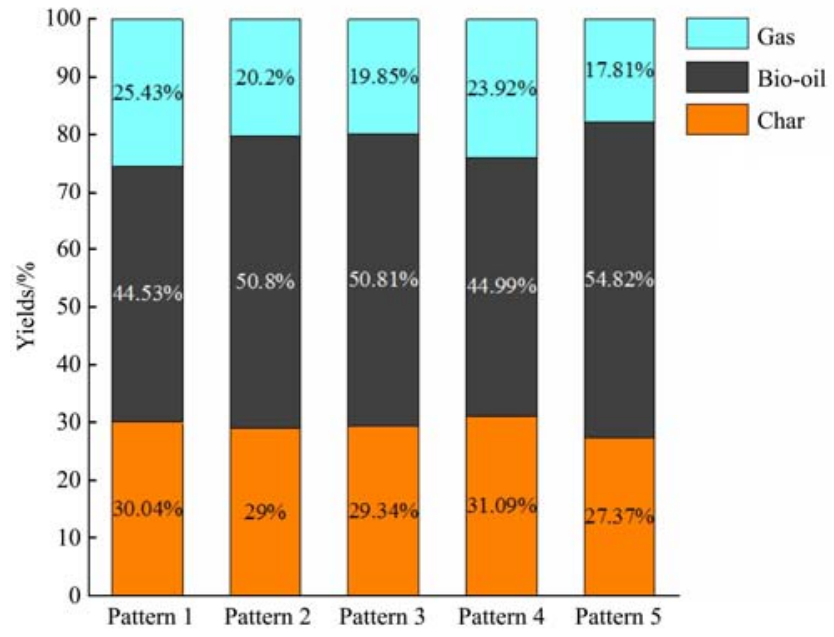

Figure 3 Product yield distributions of white pine wood under different heating patterns

Under the same pyrolysis conditions, different constant heating rates resulted in changes of the product distributions. In Patterns 4,3 and 5 , constant heating rates were used at $2.3^{\circ} \mathrm{C} / \mathrm{min}$, $4.6^{\circ} \mathrm{C} / \mathrm{min}$ and $9.2^{\circ} \mathrm{C} / \mathrm{min}$, respectively. Raise the heating rate increased the bio-oil yield from $44.99 \%$ to $54.82 \%$. However, the yields of gas (from $23.92 \%$ to $17.81 \%$ ) and char (from $31.09 \%$ to 27.37\%) showed the opposite trends. Therefore, it can be concluded that a higher heating rate is not conducive to the production of charcoal and pyrolysis gas in the process of slow pyrolysis. Numerous studies made the similar observations that high heating rate results in higher liquid yields and less solid yield and non-condensable gases ${ }^{[26-28]}$.

To further explore the influence of heating rate on pyrolysis process, thermo-gravimetric experiments were conducted to get the TGA and DTG curves of Patterns 1, 2 and 3 in Figure 4, same pyrolysis time and holding time were used. The results showed that different heating rates had a significant impact on weight loss behavior. The maximum loss of the three heating methods occurred at the range of $350^{\circ} \mathrm{C}-365^{\circ} \mathrm{C}$ and the maximum weight losses were recorded at $24.61 \mathrm{~min}$ (Pattern 1), $102.15 \mathrm{~min}$ (Pattern 2) and $72.22 \mathrm{~min}$ (Pattern 3), respectively. This is also confirmed by the research of Quan et al. ${ }^{[29]}$ that $350^{\circ} \mathrm{C}-365^{\circ} \mathrm{C}$ are the main temperature range for pyrolysis of cellulose and part of lignin in this temperature range. The weight losses below $240^{\circ} \mathrm{C}$ were mainly caused by the moisture evaporation and decomposition of hemicellulose. The decomposition of the cellulose and lignin occurred when the temperature was higher than $240^{\circ} \mathrm{C}$. Comparing to Patterns 1 and 3, Pattern 2 has the higher DTG peak point of $-1.48 \mathrm{mg} / \mathrm{min}$. While the peak point for Patterns 1 and 3 are in the vicinity of $-1.08 \mathrm{mg} / \mathrm{min}$ and $-0.65 \mathrm{mg} / \mathrm{min}$, respectively. The reason is the rapid heating stage of Pattern 2 happens after $240^{\circ} \mathrm{C}$, which is also the temperature range for decomposition of cellulose and lignin. Different biomass materials contain different contents of the cellulose, hemicelluloses and lignin, which then affected the results of the TGA and DTG. Therefore, as shown in Figure 4, DTG peaks of cellulose and lignin did not separated very clearly, which was different with the results presented by Park et al. ${ }^{[3]}$, who used garlic stems and pepper stems as feedstock.
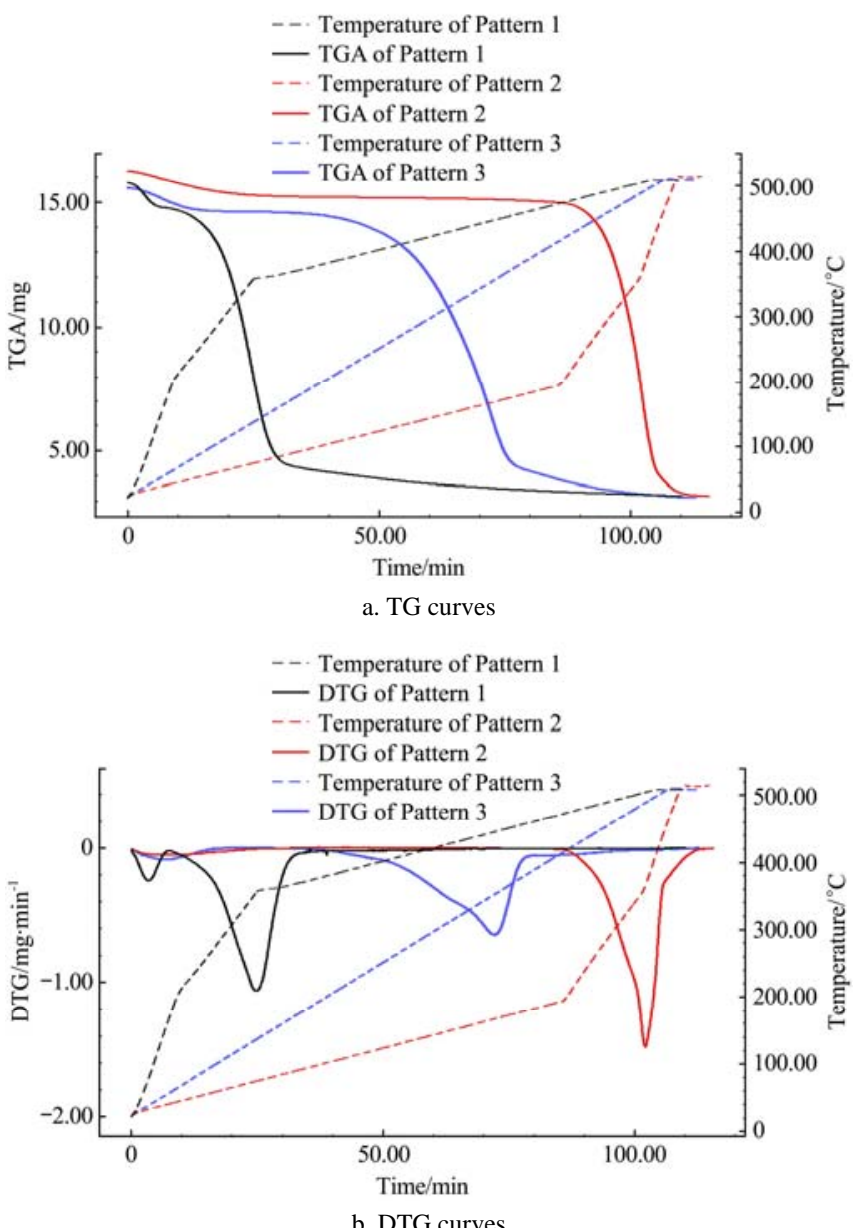

Figure 4 TG and DTG curves of samples produced by different Patterns

\subsection{Characteristics of the chars}

The results of proximate analysis, higher heating value (HHV), and elemental analysis of chars are given in Table 2. The effects of different heating patterns on chars are illustrated by the proximate and elemental analysis. 
Table 2 Characteristics of the charcoal in different pyrolysis patterns

\begin{tabular}{lccccc}
\hline $\begin{array}{c}\text { Pyrolysis } \\
\text { Procedure/wt \% }\end{array}$ & Pattern 1 & Pattern 2 & Pattern 3 & Pattern 4 & Pattern 5 \\
\hline Volatiles & 18.80 & 16.30 & 16.95 & 17.13 & 16.57 \\
Fixed carbon & 78.20 & 79.89 & 80.12 & 79.76 & 80.23 \\
Ash & 3.00 & 3.81 & 2.93 & 3.11 & 3.20 \\
HHV/MJ·kg-dry ${ }^{-1}$ & 31.50 & 31.58 & 32.11 & 32.08 & 32.44 \\
$\mathrm{C}$ & 85.82 & 84.48 & 84.74 & 85.14 & 85.74 \\
$\mathrm{H}$ & 3.15 & 3.26 & 3.17 & 3.15 & 3.20 \\
$\mathrm{O}$ & 10.59 & 11.84 & 11.78 & 11.28 & 10.76 \\
$\mathrm{~N}$ & 0.38 & 0.44 & 0.42 & 0.31 & 0.43 \\
\hline
\end{tabular}

Proximate analysis of the charcoal samples from the five patterns showed that the percentage of the volatile content in Pattern 1 (18.80\%) was similar to Pattern 4 (17.13\%), while Pattern 2 (16.30\%) was similar to Pattern 5 (16.57\%). Contents of fixed carbon content in five patterns showed no significant difference. Comparing the results in Patterns 3-5, it could be concluded that increasing heating rate resulted in a decrease in the content of the volatile matter content and increased of the content of fixed carbon content in chars. After determination of the heat value of chars, it was found that within the selected temperature range, the heat values of charcoals increased with the increase of heating rate. The higher heating rate might help fix the carbon in the charcoal and release oxygen-containing functional groups $^{[30,31]}$. The experiments of VHR showed that the impact of variable heating rate on heat value was not significant. The results of elemental analysis presented that $\mathrm{H}, \mathrm{O}$ decreased severely and the ratio of $\mathrm{C}$ element increased during biomass pyrolysis process. Regardless of the heating pattern, $\mathrm{C}$ elements of white pine increased from $49.44 \%$ to more than $84.48 \%$ and $\mathrm{H}$ element decrease from $6.33 \%$ to $3.26 \%$ or less. The value of $\mathrm{H} / \mathrm{C}$ and $\mathrm{O} / \mathrm{C}$ are consistent in five patterns which indicate that the heating rate has little effect on $\mathrm{H} / \mathrm{C}$ and $\mathrm{O} / \mathrm{C}$ within the selected heating patterns.

\subsection{Product distribution of gas and bio-oil}

\subsubsection{Distribution of pyrolysis phase products}

Besides charcoals, the characteristics of pyrolysis gas were also examined to investigate the process of gas generation. The gas sampling started when the temperature reached $90^{\circ} \mathrm{C}$ with an interval of $50 \mathrm{~mL} / 10 \mathrm{~min}$. Several main components $\left(\mathrm{CO}_{2}, \mathrm{CO}\right.$, $\mathrm{CH}_{4}$ and $\mathrm{H}_{2}$ ) were tested during pyrolysis processes. The five heating patterns resulted in the different trends of the pyrolysis gas distributions as shown in Figure 5. Except for Pattern 4, the overflow peak value (OPV) of $\mathrm{CO}_{2}$ was higher than $43.00 \%$, while the OPV of CO was higher than $42.17 \%$, and the highest value reached $45.25 \%$. In the five experiments, overflow curves of CO were similar to $\mathrm{CO}_{2}$ with the OPV of $40 \%-50 \%$. This observation was similar to the results by $\mathrm{Wu}$ et al. ${ }^{[26]}$ In Pattern 4 (with constant heating rate of $2.3^{\circ} \mathrm{C} / \mathrm{min}$ ), due to the slow gas overflowing rate and potential dilution by the carrier gas, the OPV was generally lower than that of other four heating patterns. After analysis of the gas products, it can be concluded that regardless of the heating patterns during slow pyrolysis, the $\mathrm{CO}_{2}$ and $\mathrm{CO}$ was released as the main components of the early stage, followed by $\mathrm{CH}_{4}$ after $220^{\circ} \mathrm{C}$. The OPV of $\mathrm{CH}_{4}$ was observed in the range of $430^{\circ} \mathrm{C}-520^{\circ} \mathrm{C}$ and higher than $20 \%$ except Pattern 4 . The OPV of $\mathrm{H}_{2}$ is obtained in high temperature range.

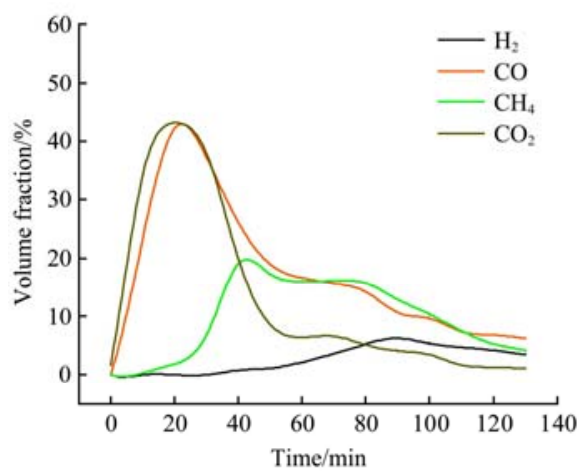

a. Pattern 1 of white pines

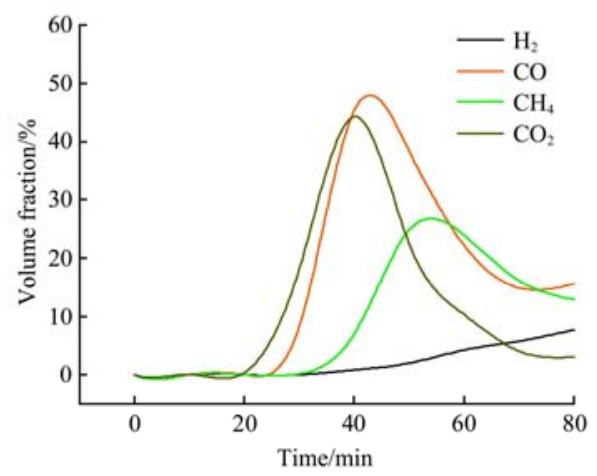

b. Pattern2 of white pines

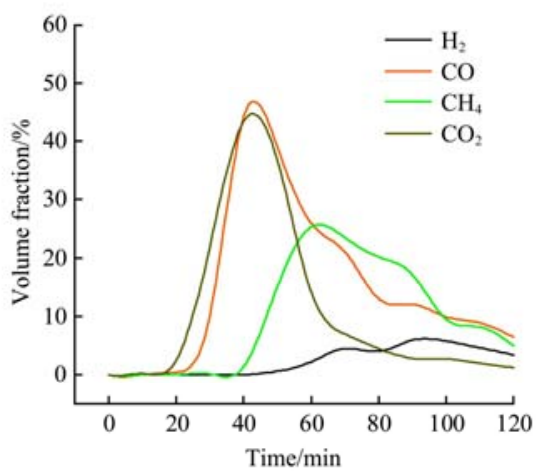

c. Pattern3 of white pines

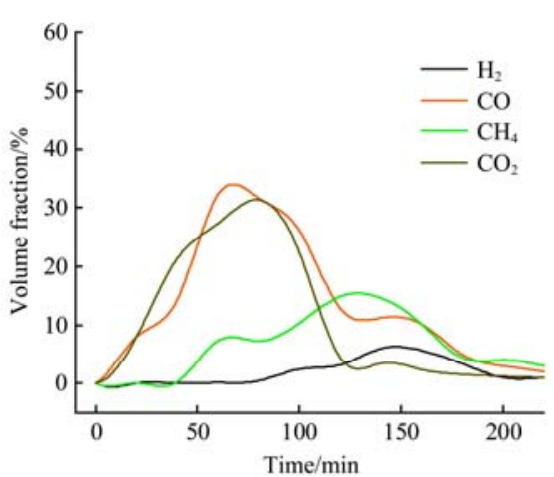

d. Pattern 4 of white pines

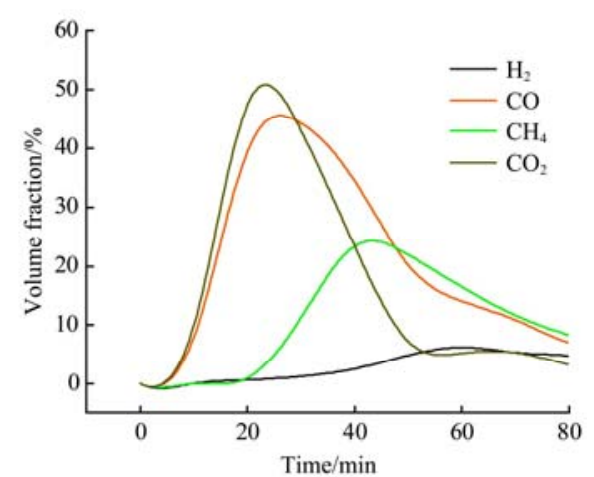

e. Pattern 5 of white pines

Figure 5 Distributions of pyrolysis gases with Patterns 1-5

\subsubsection{Chemical component of bio-oil}

By comparing three kinds of heavy oil of white pine bio-oil derived from Patterns 1-3, significant differences were spotted. Based on the sample analysis by GC-MS, more than 50 kinds of constituents were identified including many organic acids, ketones, phenols and polycyclic aromatic hydrocarbons. Comparison of the high content constituents in two samples was shown in Table 4, the organics in the category of C3-C6 generated by Pattern 1 were generally higher than that by Pattern 2 . The acetic acid content by Pattern 1 was $19.19 \%$, which was $5.52 \%$ higher than content of by 
Pattern 2. The acetol content of $18.58 \%$ in Pattern 1 was $6.00 \%$ higher than that in Pattern 2. However, in Pattern 2, the organic products of C10-C20 were generally higher than Pattern 1 . The formulae of polycyclic aromatic hydrocarbons were more complicated and the distinction was clearly reflected in Figure 6. This pattern generates more C16-C21 organic molecules including $\mathrm{C}_{21} \mathrm{H}_{30} \mathrm{O}_{2}$ (CAS: 1235-74-1), $\mathrm{C}_{20} \mathrm{H}_{28} \mathrm{O}_{2}$ (CAS: 5155-70-4), $\mathrm{C}_{18} \mathrm{H}_{18}$ (CAS: 66552-97-4), etc. These ingredients were not detected in the bio-oil produced via Pattern 1.

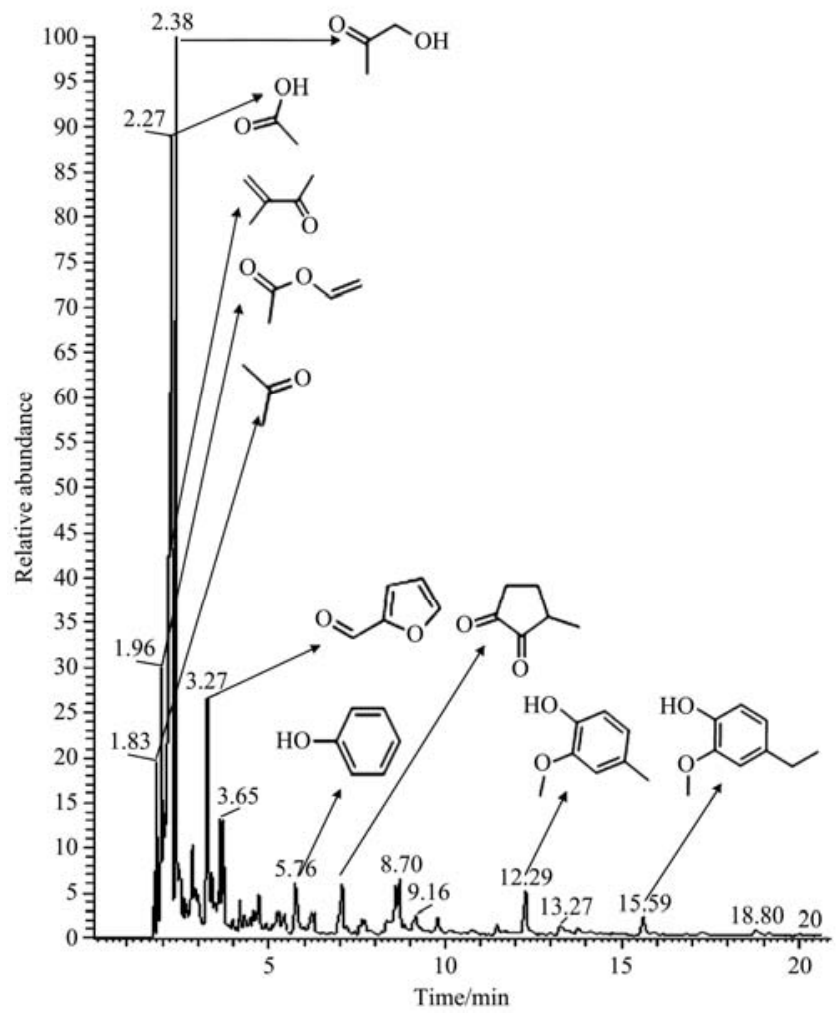

a. Pattern 1

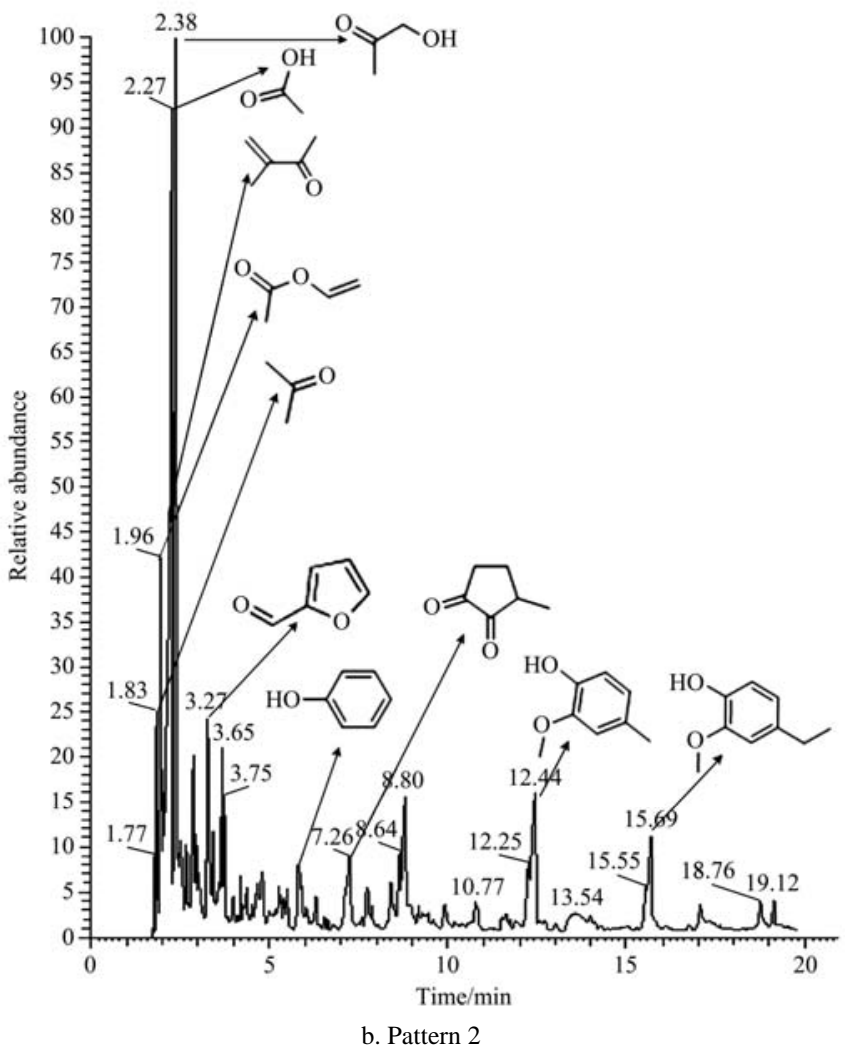

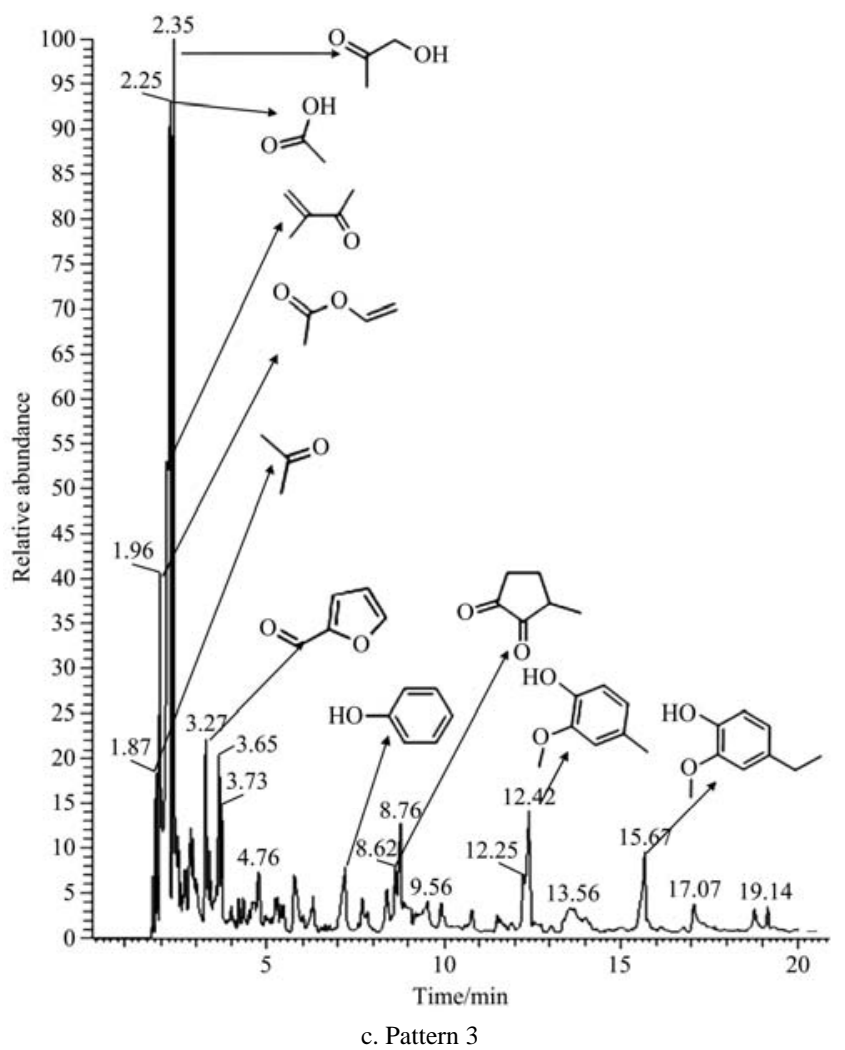

Figure 6 GC-MS spectrum of bio-oil produce

The reason for this distinction was that the decomposition of the hemicellulose resulted in higher percentage of small organic molecules, which discharged during rapid heating rate under low temperatures. However, during lignin and cellulose pyrolysis, organic macromolecules were generated in the high temperature range. Gas products (including condensable and non-condensable gases) were released slowly with slow reaction caused by low heating rate. Thus, the gas products are possibly further cleaved to form simple compounds, which were then removed by the carrier gas eventually. Organic macromolecular volatiles were generated by Pattern 2 in the high-temperature range, without adequate re-cracking, they were removed from the fixed bed quickly by the other products or the carrier gas. Eventually, more organic macromolecules were condensed and collected. GC-MS curve of Pattern 3 was similar to that of the Pattern 2, where lower 2 -propanone $(0.6 \%)$ and acetic acid vinyl ester (3.8\%) presented in the product.

Table 4 Main components of the bio-oil and their contents

\begin{tabular}{|c|c|c|c|c|}
\hline Formula & & $\begin{array}{c}\text { Pattern } 1 \\
/ \%\end{array}$ & $\begin{array}{c}\text { Pattern } 2 \\
/ \%\end{array}$ & $\begin{array}{c}\text { Pattern } 3 \\
\quad / \%\end{array}$ \\
\hline 2-propanone & $\mathrm{C}_{3} \mathrm{H}_{6} \mathrm{O}$ & 2.37 & 1.63 & 0.6 \\
\hline Acetic acid vinyl ester & $\mathrm{C}_{4} \mathrm{H}_{6} \mathrm{O}_{2}$ & 5.29 & 4.40 & 3.8 \\
\hline Isopropenyl methyl ketone & $\mathrm{C}_{5} \mathrm{H}_{8} \mathrm{O}$ & 5.11 & 3.98 & 3.47 \\
\hline Ethanoic acid & $\mathrm{C}_{2} \mathrm{H}_{4} \mathrm{O}_{2}$ & 19.19 & 13.67 & 14.36 \\
\hline Acetol & $\mathrm{C}_{3} \mathrm{H}_{6} \mathrm{O}_{2}$ & 18.58 & 12.57 & 12.89 \\
\hline 2-Furancarboxaldehyde & $\mathrm{C}_{5} \mathrm{H}_{4} \mathrm{O}_{2}$ & 7.8 & 4.04 & 4.59 \\
\hline Carbolic acid & $\mathrm{C}_{6} \mathrm{H}_{6} \mathrm{O}$ & 2.82 & 2.11 & 2.61 \\
\hline 1, 2-Benzenediol & $\mathrm{C}_{6} \mathrm{H}_{6} \mathrm{O}_{2}$ & l & 2.44 & 2.74 \\
\hline 3-Methyl-1, 2-Cyclopentanedione & $\mathrm{C}_{6} \mathrm{H}_{8} \mathrm{O}_{2}$ & 3.10 & 3.53 & 3.87 \\
\hline 2-Methoxy-4-Methylphenol & $\mathrm{C}_{8} \mathrm{H}_{12} \mathrm{O}_{2}$ & 2.92 & 5.54 & 4.81 \\
\hline p-Ethylguaiacol & $\mathrm{C}_{9} \mathrm{H}_{12} \mathrm{O}_{2}$ & 1.29 & 4.76 & 4.58 \\
\hline
\end{tabular}




\section{Conclusions}

Based on the analysis of the char characteristics, yields of non-condensable gases, and the production efficiency, DHR is proved to be the optimal pyrolysis pattern in this study, which showed three-phase yields of $30.04 \%$ charcoal, $25.43 \%$ gas, and $44.53 \%$ bio-oil, respectively. Thermo-gravimetric analysis reveals that the heating pattern significantly affected the weight loss behavior, and the results of the elemental analysis shows that carbon enrichment, dehydrogenation, and deoxygenation occurred in the process of pyrolysis. Through pyrolysis gas analysis, it can be concluded that regardless of the heating rate during slow pyrolysis, the gas releasing starts with $\mathrm{CO}_{2}$ and $\mathrm{CO}$, followed by $\mathrm{CH}_{4}$ after $220^{\circ} \mathrm{C}$. The $\mathrm{OPV}$ of $\mathrm{CH}_{4}$ was observed at $430^{\circ} \mathrm{C}-520^{\circ} \mathrm{C}$. The $\mathrm{H}_{2}$ production peaks were recorded at high temperatures region. Higher percentage of small molecule organic compounds and lower percentage of polycyclic aromatic hydrocarbons are formed by DHR.

\section{Acknowledgements}

The authors would like to acknowledge the financial support from Project 948 (2016-X55) and special fund for agro-scientific research in the public interest (201503135).

\section{[References]}

[1] Liu Z, Han G. Production of solid fuel biochar from waste biomass by low temperature pyrolysis. Fuel, 2015; 158: 159-165.

[2] Hu S, Jess A, Xu M. Kinetic study of Chinese biomass slow pyrolysis: Comparison of different kinetic models. Fuel, 2007; 86(17-18): 2778-2788.

[3] Park Y K, Yoo M L, Lee H W, Park S H, Jung S C, Park S S, et al. Effects of operation conditions on pyrolysis characteristics of agricultural residues. Renewable Energy, 2012; 42: 125-130.

[4] Zhang H, Zhang K, Zhou X H, Hu J J, Jing Y Y, Liu S Y. Thermal properties of biomass tar at rapid heating rates. Int J Agric \& Biol Eng, 2014; 7(2): 101-107.

[5] Paethanom A, Yoshikawa K. Influence of pyrolysis temperature on rice husk char characteristics and its tar adsorption capability. Energies, 2012; 5(12): 4941-4951.

[6] Agirre I, Griessacher T, Roesler G, Antrekowitsch J. Production of charcoal as an alternative reducing agent from agricultural residues using a semi-continuous semi-pilot scale pyrolysis screw reactor. Fuel Processing Technology, 2013;106: 114-121.

[7] Wannapeera J, Fungtammasan B, Worasuwannarak N. Effects of temperature and holding time during torrefaction on the pyrolysis behaviors of woody biomass. Journal of Analytical and Applied Pyrolysis, 2011; 92(1): 99-105.

[8] Angin D. Effect of pyrolysis temperature and heating rate on biochar obtained from pyrolysis of safflower seed press cake. Bioresource Technology, 2013; 128: 593-597.

[9] Zhou R. Effects of reaction temperature, time and particle size on switchgrass microwave pyrolysis and reaction kinetics. Int J Agric \& Biol Eng, 2013; 6(1): 53-61.

[10] Onay O. Influence of pyrolysis temperature and heating rate on the production of bio-oil and char from safflower seed by pyrolysis, using a well-swept fixed-bed reactor. Fuel Processing Technology, 2007; 88(5): 523-531.

[11] Haykiri-Acma H, Yaman S, Kucukbayrak S. Effect of heating rate on the pyrolysis yields of rapeseed. Renewable Energy, 2006; 31(6): 803-810.

[12] Weerachanchai P, Tangsathitkulchai C, Tangsathitkulchai M. Characterization of products from slow pyrolysis of palm kernel cake and cassava pulp residue. Korean Journal of Chemical Engineering, 2011; 28(12): 2262-2274.

[13] Doumer M E, Carbajal Arizaga G G, da Silva D A, Yamamoto C I, Novotny E H, Santos J M, et al. Slow pyrolysis of different Brazilian waste biomasses as sources of soil conditioners and energy, and for environmental protection. Journal of Analytical and Applied Pyrolysis, 2015; 113: 434-443.

[14] Demiral I, Eryazici A, Sensoz S. Bio-oil production from pyrolysis of corncob (Zea mays L.). Biomass \& Bioenergy, 2012; 36: 43-49.

[15] Crombie K, Masek O. Investigating the potential for a self-sustaining slow pyrolysis system under varying operating conditions. Bioresource Technology, 2014; 162: 148-156.

[16] Arias B, Pevida C, Fermoso J, Plaza M G, Rubiera F, Pis J J. Influence of torrefaction on the grindability and reactivity of woody biomass. Fuel Processing Technology, 2008; 89(2): 169-175.

[17] Burhenne L, Messmer J, Aicher T, Laborie M P. The effect of the biomass components lignin, cellulose and hemicellulose on TGA and fixed bed pyrolysis. Journal of Analytical and Applied Pyrolysis, 2013; 101: 177-184.

[18] Samuelsson L N, Umeki K, Babler M U. Mass loss rates for wood chips at isothermal pyrolysis conditions: A comparison with low heating rate powder data. Fuel Processing Technology, 2017; 158: 26-33.

[19] Chen D, Zhou J, Zhang Q. Effects of heating rate on slow pyrolysis behavior, kinetic parameters and products properties of moso bamboo. Bioresource Technology, 2014; 169: 313-319.

[20] Pallab D, Pankaj T. Valorization of packaging plastic waste by slow pyrolysis. Resources, Conservation \& Recycling, 2018; 128: 69-77.

[21] Erwei L, Yang Z, Yang P, Xun G. In situ structural changes of crystalline and amorphous cellulose during slow pyrolysis at low temperatures. Fuel, 2018; 216: 313-321.

[22] Park D K, Kim S D, Lee S H, Lee J G. Co-pyrolysis characteristics of sawdust and coal blend in TGA and a fixed bed reactor. Bioresource Technology, 2010; 101(15): 6151-6156.

[23] Stefanidis S D, Kalogiannis K G, Iliopoulou E F, Michailof C M, Pilavachi P A, Lappas A A. A study of lignocellulosic biomass pyrolysis via the pyrolysis of cellulose, hemicellulose and lignin. Journal of Analytical and Applied Pyrolysis, 2014;105: 143-150.

[24] Chen D Y, Li Y J, Cen K H, Luo M, Li H Y, et al. Pyrolysis polygeneration of poplar wood: Effect of heating rate and pyrolysis temperature. Bioresource Technology, 2016; 218: 780-788.

[25] Jorge M, Brennan P, David R, Farid C J, Manuel G P. Effect of temperature and heating rate on product distribution from the pyrolysis of sugarcane bagasse in a hot plate reactor. Journal of Analytical and Applied Pyrolysis, 2017; 123: 347-363.

[26] Wu C, Budarin V L, Gronnow M J, de Bruyn M, Onwudili J A, Clark J H, et al. Conventional and microwave-assisted pyrolysis of biomass under different heating rates. Journal of Analytical and Applied Pyrolysis, 2014; 107: 276-283.

[27] Chen C, Wang J, Liu W, Zhang S, Yin J, Luo G, et al. Effect of pyrolysis conditions on the char gasification with mixtures of $\mathrm{CO}_{2}$ and $\mathrm{H}_{2} \mathrm{O}$. Proceedings of the Combustion Institute, 2013; 34: 2453-2460.

[28] Guizani C, Sanz F J E, Salvador S. Effects of $\mathrm{CO}_{2}$ on biomass fast pyrolysis: Reaction rate, gas yields and char reactive properties. Fuel, 2014; 116: 310-320.

[29] Quan C, Gao N B, Song Q B. Pyrolysis of biomass components in a TGA and a fixed-bed reactor: Thermochemical behaviors, kinetics, and product characterization. Journal of Analytical and Applied Pyrolysis, 2016; 121: 84-92.

[30] Park J, Lee Y, Ryu C, Park Y K. Slow pyrolysis of rice straw: Analysis of products properties, carbon and energy yields. Bioresource Technology, 2014; 155: 63-70.

[31] Wei L, Liang S, Guho N M, Hanson A J, Smith M W, Garcia-Perez M, et al. Production and characterization of bio-oil and biochar from the pyrolysis of residual bacterial biomass from a polyhydroxyalkanoate production process. Journal of Analytical and Applied Pyrolysis, 2015; 115: 268-278. 